\section{Coronavirus como amenaza a la salud pública}

\section{Coronavirus as a threat to public health}

\section{Señor Editor:}

Preocupación ha causado durante las últimas semanas el brote de un virus en Wuhan, ciudad de $11 \mathrm{mi}-$ llones de habitantes ubicada en la Provincia de Hubei, China $^{1-3}$. Este agente patógeno, de la familia Coronaviridae, puede generar neumonía y ha producido miles de muertos y de contagiados. El objetivo de esta Carta al Editor es discutir las principales características de este virus y cómo éste puede amenazar la salud pública.

Los coronavirus (CoVs) son virus ARN monocatenarios de sentido positivo (Figura 1A), poseen envoltura, son altamente diversos y causan trastornos respiratorios, digestivos, hepáticos y neurológicos de severidad variable en un amplio rango de especies animales, incluyendo al ser humano, en quien pueden causar enfermedades graves ${ }^{4}$. Los CoVs se agrupan en cuatro géneros: Alfacoronavirus, Betacoronavirus, Gammacoronavirus y Deltacoronavirus ${ }^{4}$. Respecto a los Betacoronavirus, dos de ellos han sido de gran interés para la comunidad científica y la salud mundial en los últimos diecisiete años: el causante del síndrome respiratorio agudo severo (conocido como SARS-CoV) ${ }^{4}$ y el causante del síndrome respiratorio del Medio Oriente (conocido como MERS-CoV) ${ }^{4}$.

Se sabe que tanto SARS-CoV ${ }^{2,5,6}$ como MERS-CoV ${ }^{2}$ son de origen zoonótico. Una zoonosis es aquella condición en la cual los patógenos causantes de enfermedad poseen, en general, un reservorio animal silvestre ${ }^{5}$; $y$ a partir de este reservorio animal, que es generalmente asintomático, el patógeno puede ser transmitido directamente a los seres humanos o a animales domésticos ${ }^{5}$, los que a su vez pueden transmitirlo a las personas ${ }^{5}$. Los animales que transmiten virus zoonóticos son usualmente vertebrados ${ }^{4}$, por ejemplo, murciélagos y civetas de las palmeras $s^{1,2,5}$ en el caso de SARS-CoV, y camellos y dromedarios ${ }^{2}$ en el caso de MERS-CoV (Figura 1B). 


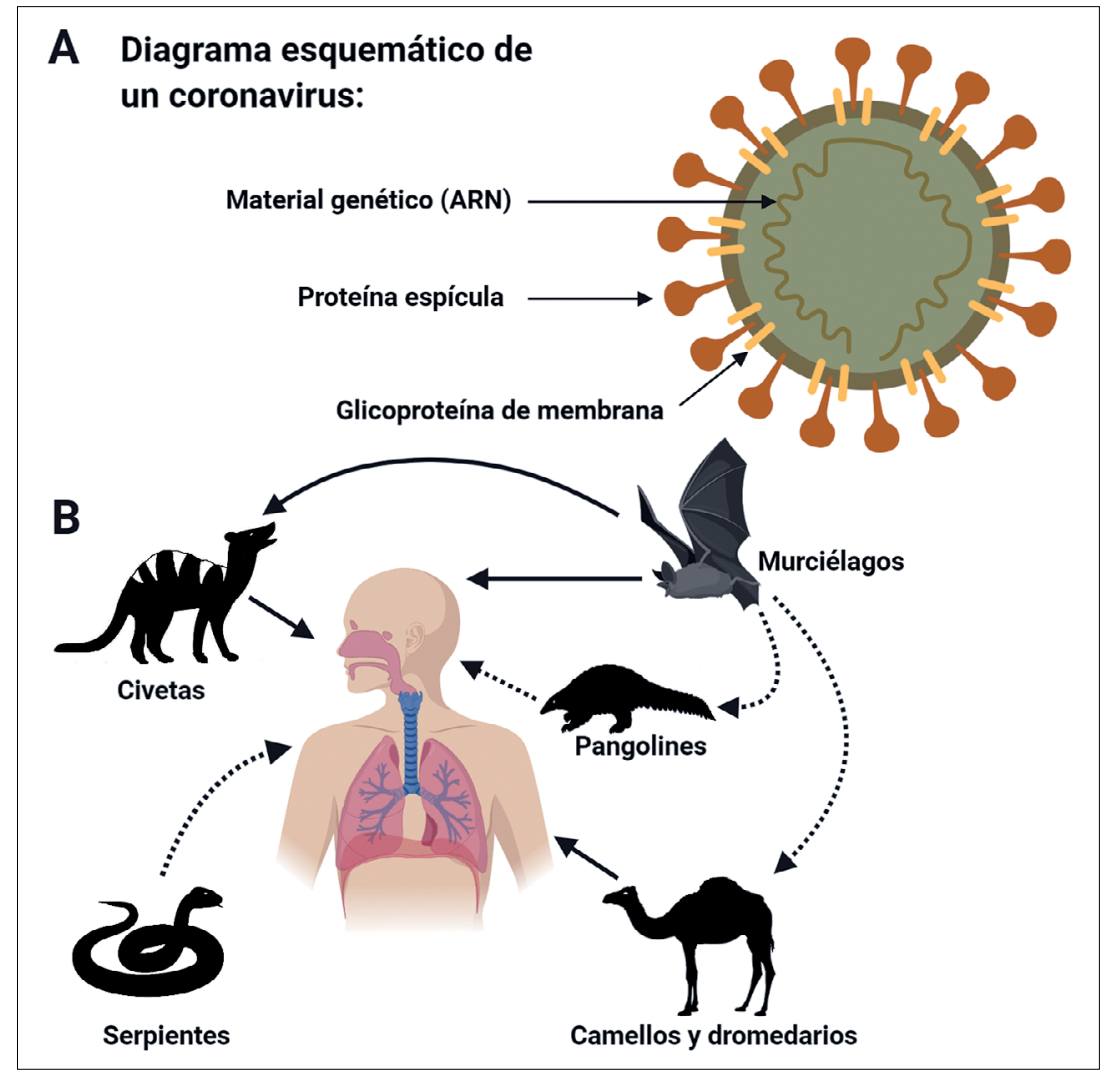

Figura 1. A. Esquema general de un coronavirus. Se denominan «coronavirus» debido al aspecto de «corona» que presenta su estructura. B. Los coronavirus corresponderían a virus zoonóticos. Las líneas continuas denotan vías de transmisión comprobadas y las discontinuas, aquellas aún no totalmente comprobadas. Figura creada utilizando biorender.com
Habiéndose ya descartado la gripe humana y aviar ${ }^{2}$, el SARS-CoV ${ }^{2}$ y el MERS-CoV ${ }^{2}$, se ha reportado ${ }^{2,3,6}$ que el coronavirus responsable del brote en Wuhan es un Betacoronavirus del grupo $2 \mathrm{~B}^{2}$. Con una secuencia genética al menos 70\% similar al SARS-CoV, la OMS lo denominó SARS-CoV-2 (inicialmente 2019-nCoV2). La patología que produce se denomina enfermedad por coronavirus (COVID 19) y sus síntomas incluyen incluyen fiebre ( $>90 \%$ de los casos), malestar, infiltrados pulmonares al efectuar radiografía de tórax, tos seca $(80 \%)$, disnea $(20 \%)$ y dificultad respiratoria $(15 \%)^{1,2,6}$. Si bien las características etiológicas de este síndrome respiratorio son aún bastante desconocidas ${ }^{6}$, se ha propuesto que el origen del coronavirus causante tendría un origen específico: animales infectados que se venden vivos en el Mercado Mayorista de Mariscos Huanan en Wuhan ${ }^{1-3}$, el cual ha sido cerrado para evitar más contagios ${ }^{1,6}$, permitiendo esto también efectuar investigaciones, saneamiento ambiental y desinfección ${ }^{2}$. Por su parte, la ciudad ha sido puesta en cuarentena. Se cree que el reservorio natural del SARS-CoV-2 serían murciélagos $^{1}$, e intermediarios serían serpientes u otros animales (Figura 1B).

Frente a este tipo de brotes epidémicos la disponibi- lidad de información oportuna y veraz es fundamental. Recientemente en The British Medical Journal ${ }^{3}$ se ha criticado que parte de la información acerca de este virus no se ha liberado a tiempo ${ }^{3}$, información que es fundamental para tomar las mejores decisiones en el área de Salud Pública ${ }^{3}$. A la fecha, 76 países (incluido Chile) han reportado casos de COVID-19 y la OMS ya ha declarado emergencia de salud pública internacional. El avance de este virus ha hecho cuestionarse a algunos investigadores ${ }^{6}$ sobre cuán rápidamente estos nuevos agentes patógenos pueden aparecer y diseminarse y cómo éstos podrían llegar a constituir una seria amenaza para la población mundial. Se debe tener en cuenta que las enfermedades zoonóticas son un desafío constante a la seguridad de la salud global ${ }^{2,5}$, realidad que requiere permanentes medidas de prevención y de respuesta oportuna ante epidemias que pueden convertirse en pandemias. Es importante considerar lo propuesto por algunos investigadores ${ }^{2}$ respecto a enfrentar estas amenazas mediante un esfuerzo colaborativo bajo el enfoque de «Una Sola Salud» (One Health), el cual integra la salud humana, animal y ambiental ${ }^{2}$, y es especialmente apropiado para las enfermedades zoonóticas que amenazan a la humanidad. Además, los organismos 
de salud públicos y privados así como las instituciones educativas deben poner especial énfasis en las medidas que eviten más contagios.

Agradecimientos: A los doctores Renán Orellana, Edgardo Rojas y Carola Mantellero (DCQyB, UBO) por sus útiles comentarios. A la Dra. Lisbell Estrada (Facultad de Ciencias de la Salud, UBO) por su ayuda con el programa BIORENDER.

Manuel E. Cortés ${ }^{1, a}$

${ }^{1}$ Departamento de Ciencias Químicas y Biológicas (DCQyB), Programa Magíster en Ciencias QuímicoBiológicas \& Programa Doctorado en Educación, Universidad Bernardo O'Higgins (UBO).

${ }^{a}$ Biólogo, Profesor de Química y Biología, Ingeniero (E) en Prevención de Riesgos (registrado en SEREMI

Salud-RM), M.B.A., M.Sc., Ph.D.

\section{Referencias}

1. Cohen J, Normile D. New SARS-like virus in China triggers alarm. Science 2020; 367 (6475): 234-5.

2. Hui DS, I Azhar E, Madani TA, Ntoumi F, Kock R, Dar O, et al. The continuing 2019-nCoV epidemic threat of novel coronaviruses to global health -The latest 2019 novel coronavirus outbreak in Wuhan, China. Int J Infect Dis 2020; 91 (febrero): 264-6.

3. Parry J. Pneumonia in China: lack of information raises concerns among Hong Kong health workers. BMJ 2020; 368 (enero): $\mathrm{m} 56$.

4. Zumla A, Chan JFW, Azhar EI, Hui DSC, Yuen K-Y. Coronaviruses - drug discovery and therapeutic options. Nat Rev Drug Discov 2016; 15(5):327-47.

5. Cabello C, Cabello F. Zoonosis con reservorios silvestres: Amenazas a la salud pública y a la economía. Rev Med Chile 2008; 136(3): 385-93.

6. Bogoch II, Watts A, Thomas-Bachli A, Huber C, Kraemer MUG, Khan K. Pneumonia of Unknown Etiology in Wuhan, China: Potential for International Spread Via Commercial Air Travel. J Travel Med 2020; doi: 10.1093/ jtm/taaa008/5704418. 